\title{
Minifragment T-plate Fixation: An Alternative Method for Medial Malleolus Fracture Fixation
}

\author{
${ }^{1}$ Harminder S Sohal, ${ }^{2}$ Radhe S Garg, ${ }^{3}$ Sanjeev Jindal, ${ }^{4}$ Jitendra Wadhwani, ${ }^{5}$ Vivek Bansal, ${ }^{6}$ Mannan Ahmed
}

\begin{abstract}
Aim: Modern trend in the management of fractures is fast changing in favor of rigid fixation and early mobilization with minimal period of plaster immobilization. We present a prospective cohort study of fixation of medial malleolus fractures with Minifragment T-plate and its evaluation in terms of maintenance of accurate anatomical reduction, stable fixation, and early restoration of functions.
\end{abstract}

Materials and methods: A total of 25 patients of median age 45 years (22-70), with medial malleolus fractures were treated by open reduction and internal fixation using Minifragment T-plate. Outcome was evaluated using the American Orthopaedic Foot and Ankle Society (AOFAS) Ankle-Hindfoot Score.

Results: A total of $80 \%$ cases had anatomical reduction, $12 \%$ had good reduction (<2 mm displacement), $4 \%$ had fair reduction (2-5 mm displacement), and $4 \%$ had poor reduction (>5 mm displacement). After 6 months follow-up, outcome was excellent in 20 cases ( $80 \%), 3$ cases $(12 \%)$ had good result, and 2 cases $(8 \%)$ had fair result according to AOFAS score. Out of 25 cases, in 2 cases ( $8 \%$ ) infection occurred, 6 cases $(24 \%)$ had limitation of movements, 1 case $(4 \%)$ had instability at ankle, and 2 cases ( $8 \%$ ) had delayed union of fracture.

Conclusion: Weighing the advantages and disadvantages of fixation with Minifragment T-plate, it can be safely concluded that Minifragment T-plate can be an effective alternative option in the management of medial malleolus fractures. At the same time, it is warned that this technique should not be used indiscriminately without technical skill.

Clinical significance: Minifragment T-plate fixation provides rigid fixation along with early return of movements with limited period of immobilization. Studying this alternative method expands the present knowledge for management of medial malleolus fractures.

\footnotetext{
${ }^{1}$ Professor and Head, ${ }^{2}$ Professor, ${ }^{3,5,6}$ Senior Resident, ${ }^{4}$ Junior Resident

1,2Department of Orthopaedics, Government Medical College and Hospital, Amritsar, Punjab, India

${ }^{3-5}$ Department of Orthopaedics, Pandit Bhagwat Dayal Sharma Post Graduate Institute of Medical Sciences, Rohtak, Haryana India

${ }^{6}$ Department of Orthopaedics, ESI Hospital, Basai Darapur Delhi, India

Corresponding Author: Sanjeev Jindal, Senior Resident Department of Orthopaedics, Pandit Bhagwat Dayal Sharma Post Graduate Institute of Medical Sciences, Rohtak, Haryana, India Phone: +918059828485, e-mail: jindal_dr@yahoo.co.in
}

Keywords: AOFAS Ankle-Hindfoot Score, Cedell and Phillips criteria, Cohort study, Herscovici classification, Medial malleolus fracture, Minifragment T-plate, Modified Kristensen.

How to cite this article: Sohal HS, Garg RS, Jindal S, Wadhwani J, Bansal V, Ahmed M. Minifragment T-plate Fixation: An Alternative Method for Medial Malleolus Fracture Fixation. J Foot Ankle Surg (Asia-Pacific) 2016;3(1):10-14.

Source of support: Nil

Conflict of interest: None

\section{INTRODUCTION}

In the modern era of rapid industrialization, fast moving vehicular traffic, and mechanized agricultural methods, trauma of different kinds including fracture of bones is becoming more and more common. The osteoarticular fractures are among the common fractures that one comes across while dealing with roadside accidents, and these fractures have been rightly called the "problem fractures." Fractures of the malleoli form the major chunk of such problem fractures that can leave the person partially crippled if not treated well. The problem of ankle injuries can be traced back to antiquity. Evidence of healed ankle fractures has been found in the remains of mummies from ancient Egypt. ${ }^{1}$

Recent understanding of patient-reported outcomes along with improved implants and fixation techniques has led to an increased trend toward surgical fixation for most unstable ankle fracture patterns despite patient age. Unimalleolar fractures tend to be the most common fractures accounting for as much as $70 \%$ of all ankle fractures. ${ }^{2,3}$

Different techniques of internal fixation of these fractures have been described in the past and various modifications of these have come up. The ideal procedure would be one in which there is good anatomical reduction, secure fixation, least morbidity, and excellent functional results. The latest technique of open reduction and internal fixation with Minifragment T-plate is a step forward in this direction (Fig. 1). ${ }^{4}$ This is one of the methods of osteosynthesis, utilizing the principle of rigid fixation and compression for internal fixation of fractures. The possible advantage over standard tension band wiring and screw fixation can be more rigidity of fixation and better maintenance of reduction with early mobilization. The rigidity achieved by this method 


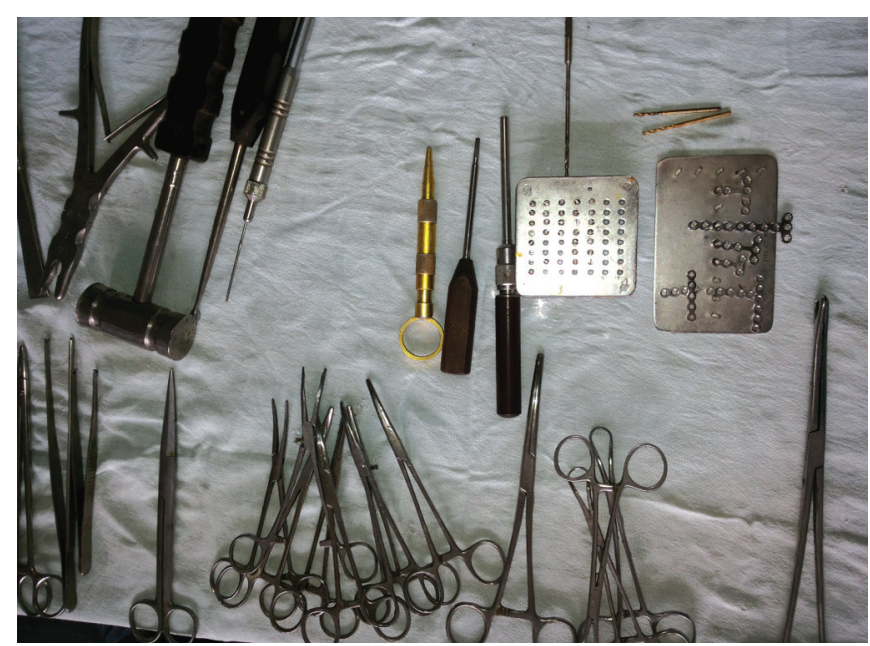

Fig. 1: Instrumentation set for Minifragment T-plate fixation

is utilized with advantage for active functional gain throughout the bone healing phase.

The present study is a prospective study where we aimed to evaluate the fixation of medial malleolus fractures with minifragment T-plate in terms of its efficacy, maintenance of accurate anatomical reduction, stable fixation, with early restoration of functions.

\section{MATERIALS AND METHODS}

This prospective study consisted of 25 cases of either sex with fracture of medial malleolus, admitted in the Department of Orthopedics at our institution, from July 2011 to May 2013. Patients with open fractures of medial malleolus were excluded from the study. Out of 25 cases, 10 patients presented as isolated medial malleolus fractures, 12 patients as bimalleolar fractures, and 3 as bimalleolar fractures with other comorbidities. Patients admitted in emergency received first aid in the form of splintage of the part and analgesics. X-ray was taken in lateral and anteroposterior views. Patient's limb was kept elevated on splint to decrease edema following trauma. Detailed history of the patient was recorded with special mention of mode of injury. Patients were investigated completely to determine fitness for operative and anesthetic procedures. Radiological examination helped to assess the type of fracture and displacement of fractured fragments. Classification of fracture was done using Herscovici's classification. ${ }^{5}$ All other associated injuries were recorded and treated accordingly and patients were operated after preanesthetic clearance. Surgery was done in supine on a radiolucent operation table. Under all aseptic conditions, after proper painting and draping, an incision was made over the medial malleolus that extends approximately $2 \mathrm{~cm}$ proximal to the fracture line and ends just distal to the tip of the medial malleolus. The great saphenous with and its accompanying nerve were protected. The subcutaneous tissue and medial retinaculum reflected with skin to reveal the fractured medial malleolus, and the fracture was cleaned of interposing periosteum and loose debris. The displaced fragment was manipulated into position. Next, a $2.0 \mathrm{~mm}$ Minifragment T-plate is contoured so that the T-portion was bent around the distal tip of the medial malleolus and the shaft of the T-plate runs proximally along the medial border of the tibia. The $\mathrm{T}$ was also contoured into a cup shape so that it apposes the medial malleolus. Two or three $2.4 \mathrm{~mm}$ cortical screws were placed through the distal T-part of the plate to obtain distal fixation and two or three screws were used for proximal fixation. Care was taken not to cross the lateral surface of medial malleolus. Associated fracture of lateral malleolus was also fixed with help of K-wire, cancellous screw or plate (Figs 1 to 4). Wound was stitched in layers and aseptic dressing was done. At the end of the procedure, the fracture was

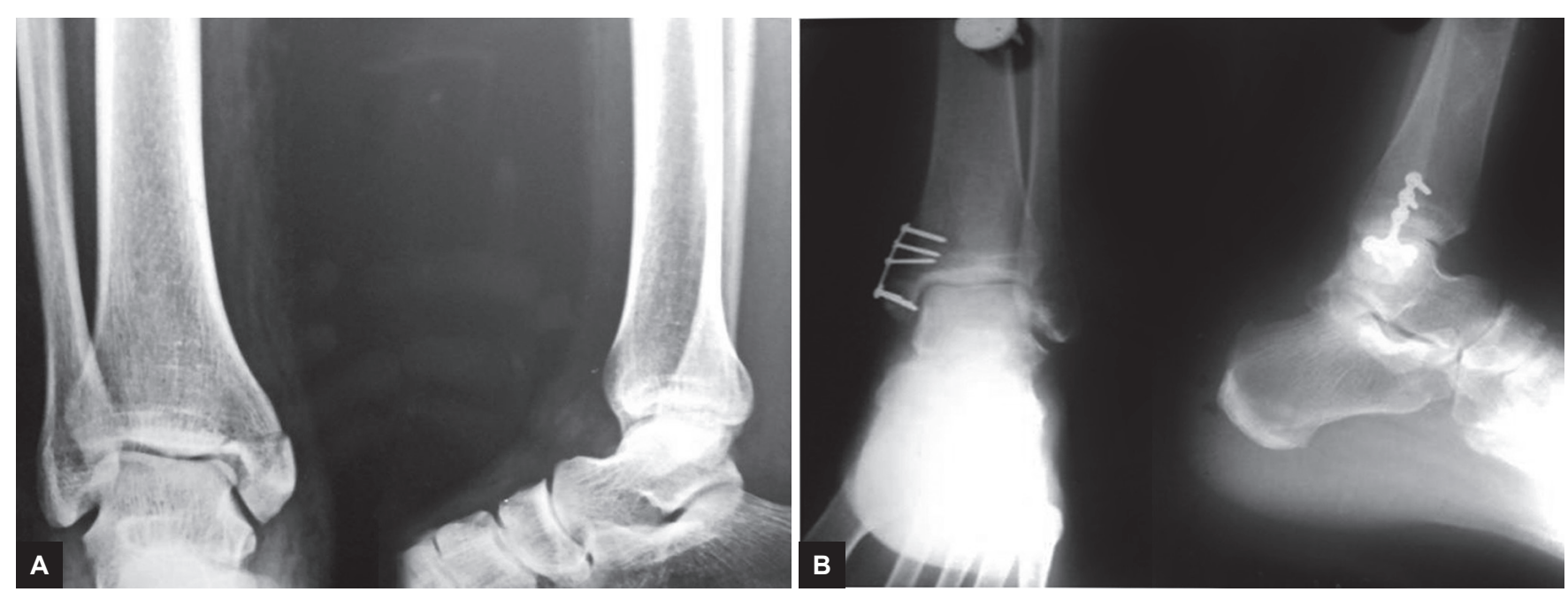

Figs 2A and B: (A) Preoperative radiograph of a 35-year-old male patient showing transverse fracture of medial malleolus on left side; and (B) postoperative radiograph of the same patient with fracture fixed with Minifragment T-plate 

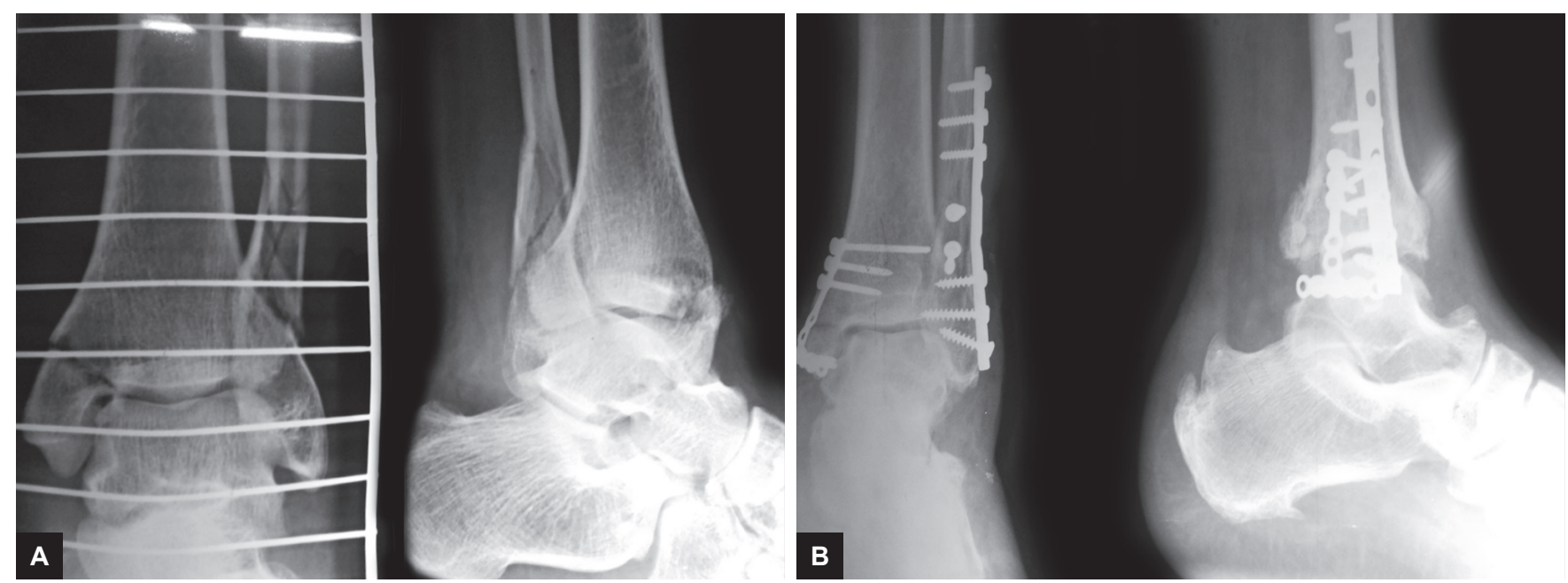

Figs 3A and B: (A) Preoperative radiograph of a 44-year-old male patient showing bimalleolar fracture of right ankle; (B) postoperative radiograph of same patient with fracture of medial malleolus fixed with Minifragment T-plate and lateral malleolus fixed with one-third tubular plate and lag screws
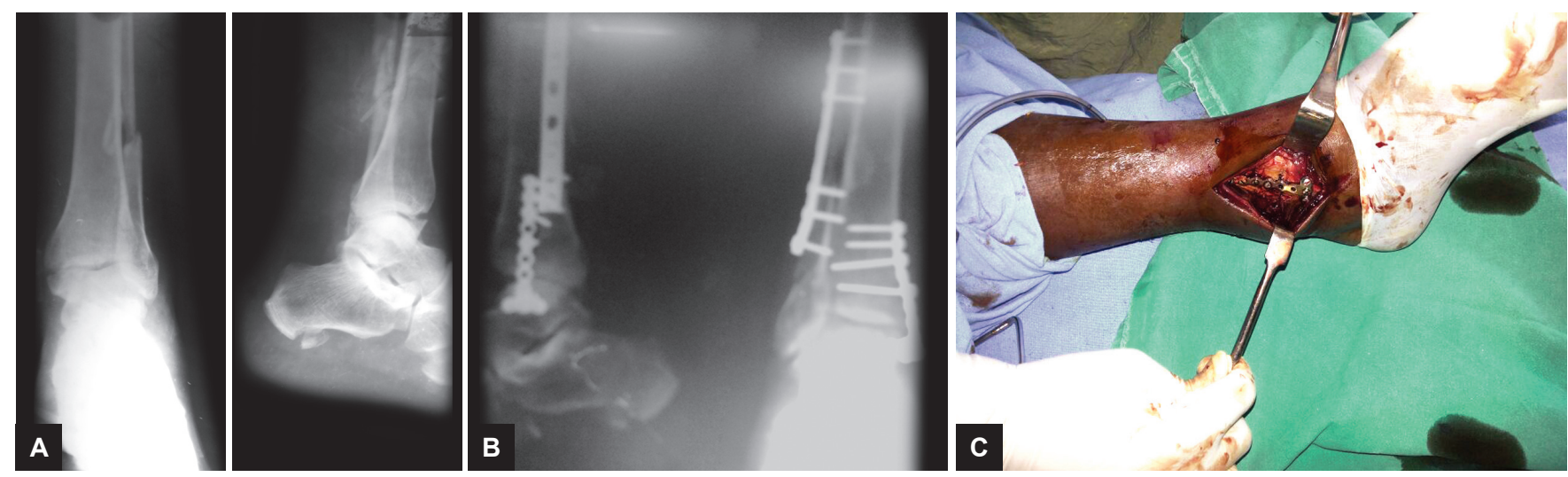

Figs 4A to C: (A) Preoperative radiograph of a 45-year-old male patient showing transverse fracture of medial malleolus with comminuted distal fibula fracture on the right side; (B) postoperative radiograph of the same patient showing fracture of medial malleolus fixed with Minifragment T-plate and distal fibula fixed with one-third tubular plate; and (C) intraoperative picture of the same patient showing incision over medial malleolus and Minifragment T-plate fixation of the same

checked for its stability and ankle movements were also checked. In all the patients, a postoperative plaster of Paris slab was given for 1 to 2 weeks. Patients were followed up at 2 weeks at first postoperatively, then after every month till first 6 months, then every 3 monthly (average follow-up of 15 months). Partial weight bearing started at 4 weeks postoperatively. At every follow-up, patients were assessed clinically for stability and range of motion and radiographically checked for the progress of fracture healing. The complications were also documented. Evaluation of results was done on basis of the AOFAS score. ${ }^{6}$ The AOFAS score was graded as poor ( $0-60$ points), fair (61-75 points), good (76-90 points), or excellent ( $>90$ points).

\section{ETHICAL AND HUMANE CONSIDERATIONS}

All patients gave written informed consent to be included in this study, and the study was authorized by the local ethical committee carried out in accordance with the
World Medical Association Declaration of Helsinki (Journal of Bone and Joint Surgery, 79-A 1089 to 1098, July 1997).

\section{RESULTS}

The patients' median age was 45 years; range 22 to 70 years. In this series, there were 22 males $(88 \%)$ and 3 females (12\%). Right side was affected in $15(60 \%)$ cases and left side in $10(40 \%)$ cases. A total of 20 patients $(80 \%)$ sustained fractures in roadside accidents. There was only one case $(4 \%)$ where the mode of injury was a direct blow over the bone. In four cases $(16 \%)$ mode of injury was fall from stairs. Majority of the fractures $(13 ; 52 \%)$ were reported in 24 hours of injury and were operated within 48 hours of injury, 5 (20\%) within a week and 7 $(28 \%)$ within 2 weeks of trauma. All the patients were discharged after 2 to 7 days of operation (average hospital stay was 3.8 days). In the present study of 25 malleolar fractures, $23(92 \%)$ showed union at 8 to 12 weeks (average 
period 10 weeks) and $2(8 \%)$ cases went into delayed union (one united after 4 months). In the present series of 25 cases of medial malleolar fractures, 24 cases (96\%) had normal sagittal movements (flexion + extension), 1 case $(4 \%)$ had moderate limitation. Out of 25 cases, 20 cases $(80 \%)$ had normal hind foot movements and 5 cases $(20 \%)$ had moderate limitation. This is because of the early active exercises started at the ankle joint and by motivating the patient to do the exercises regularly to avoid stiffness at the ankle joint.

According to Herscovici's classification, in 6 (24\%) cases it was tip avulsion, in $2(8 \%)$ cases it was intermediate fracture, in 15 (60\%) cases it was at level of plafond, and in $2(8 \%)$ cases it was above plafond.

Out of 25 cases, 23 (92\%) cases had union of fracture (8-12 weeks), 2 (8\%) cases had delayed union (13-24 weeks), and no case had nonunion. Tables 1 and 2 show distribution of radiological reduction of fracture according to modified Kristensen, Cedell and Phillips ${ }^{7-9}$ and AOFAS Ankle-Hindfoot score respectively. Table 3 shows distribution of various complications.

Table 1: Reduction of fracture on postoperative radiographs

\begin{tabular}{lll}
\hline Reduction of fragments & No. of cases & Percentage \\
\hline Anatomical & 20 & 80 \\
Good & 3 & 12 \\
Fair & 1 & 4 \\
Poor & 1 & 4 \\
\hline Total & 25 & 100 \\
\hline
\end{tabular}

Table 2: American Orthopaedic Foot and Ankle Society Ankle-Hindfoot score

\begin{tabular}{lll}
\hline Result & No. of cases & Percentage \\
\hline Excellent $(>90)$ & 23 & 80 \\
Good $(>75-90)$ & 3 & 12 \\
Fair $(>60-75)$ & 2 & 8 \\
Poor $(60$ and below) & - & - \\
\hline Total & 25 & 100 \\
\hline
\end{tabular}

Table 3: Complications

\begin{tabular}{lll}
\hline Complication & No. of cases & Percentage \\
\hline Infection & 2 & 8 \\
Limitation of movement & 6 & 24 \\
Delayed union & 2 & 8 \\
Instability & 1 & 4 \\
\hline
\end{tabular}

Table 4: Comparison of results with literature

\begin{tabular}{|c|c|c|c|c|}
\hline \multirow[b]{2}{*}{ Studies } & \multicolumn{4}{|c|}{ Results (\%) } \\
\hline & Excellent & Good & Fair & Poor \\
\hline Present study & 80 & 12 & 8 & 0 \\
\hline Thomas et $a^{13}$ & 64 & 24 & 12 & 0 \\
\hline Mak et al ${ }^{12}$ & 90 & & 0 & 10 \\
\hline Lindsjo $^{10}$ & 82 & $\varepsilon$ & & 10 \\
\hline Georgiadis and White ${ }^{10}$ & 90 & 10 & 0 & 0 \\
\hline
\end{tabular}

\section{DISCUSSION}

Our observations regarding the results of open reduction and internal fixation of medial malleolar fracture with Minifragment T-plate are comparable to the various reported studies in literature (Table 4$).{ }^{10-13}$ This can be attributed to preoperative antibiotic coverage, early surgical intervention, accurate reduction, meticulous aseptic technique, and early postoperative active exercises.

The fixation of medial malleolus fractures with Minifragment T-plate was found to be effective maintenance of accurate reduction, stable fixation, and early restoration of functions.

The study has some limitations. With the small size of the sample, it is difficult to reach a firm conclusion, but this initiative can help in future research. Costeffectiveness of Minifragment T-plate over standard tension band wiring and malleolar screw fixation was not measured. Fluoroscopic examination is advised before wound closure to assess the quality of reduction and fixation. Also, fluoroscopy guidance will help to prevent placement of any screw in ankle joint. Adequate surgical skills and surgeon's experiences with the surgical technique are necessary to achieve correct implant technique and avoid these intraoperative errors.

\section{CONCLUSION}

Weighing the advantages and disadvantages of open reduction and internal fixation with Minifragment T-plate, it can be safely concluded that Minifragment T-plate can be an effective option in the management of medial malleolar fractures. At the same time, it is warned that this technique should not be used indiscriminately without technical skills. Adequate surgical skills and surgeon's experiences with the surgical technique are necessary to achieve correct implant technique and avoid intraoperative errors. Moreover, patients' risk for complications should be evaluated more individually and taken into consideration for the concept of treatment.

\section{REFERENCES}

1. Elliot, S.; Wood, J. The archeological survey of the Nubia Report. Vol 2. Ministry of Finance, Egypt: National Printing Department; 1910. p.1907-1908.

2. Court-Brown CM, McBirnie J, Wilson G. Adult ankle fractures-an increasing problem. Acta Orthop Scand 1998 Feb;69(1):43-47.

3. Daly PJ, Fitzgerald RH, Melton LJ. Epidemiology of ankle fractures in Rochester, Minnesota. Acta Orthop Scand 1987 Oct;58(5):539-544.

4. Amanatullah DF, McDonald E, Shellito A. Effect of mini-fragment fixation on the stabilization of medial 
malleolus fractures. J Trauma Acute Care Surg 2012 Apr;72(4): 948-953.

5. Herscovici D, Scaduto JM, Infante A. Conservative treatment of isolated fractures of the medial malleolus. J Bone Joint Surg Br 2007 Jan;89(1):89-93.

6. Kitaoka HB, Alexander IJ, Adelaar RS. Clinical rating systems for the ankle-hindfoot, midfoot, hallux, and lesser toes. Foot Ankle Int 1994 Jul;15(7):349-353.

7. Cedell CA. Supination-outward rotation injuries of the ankle. A clinical and roentgenological study with special reference to the operative treatment. Acta Orthop Scand 1967; (Suppl 110):3+.

8. Kristensen TB. Fractures of the ankle. Follow up studies. Arch Surg 1956 Jul;73(1):112-121.
9. Phillips WA, Schwartz HS, Keller CS. A prospective, randomized study of the management of severe ankle fractures. J Bone Joint Surg 1985 Jan;67(1):67-78.

10. Georgiadis GM, White DB. Modified tension band wiring of medial malleolar ankle fracture. Foot Ankle Int 1995 Feb;16(2):64-68.

11. Lindsjo ULF. Operative treatment of ankle fracturedislocations (a follow up study of 306-321 consecutive cases). Clin Orthop Relat Res 1985 Oct;(199):28-38.

12. Mak KH, Chan KM, Leung PC. Ankle fractures treated with the AO principle: an experience with 116 cases. Injury 1985 Jan;16(4):265-272.

13. Meyer TL Jr, Kumler KW. ASIF technique and ankle fractures. Clin Orthop Relat Res 1980 Jul-Aug;(150):211-216. 